\title{
The role of VDC professionals in the construction industry
}

\author{
Mathias Gustafsson $^{\mathrm{a}^{*}}$, Pernilla Gluch ${ }^{\mathrm{b}}$, Sigrid Gunnemark ${ }^{\mathrm{a}}$, Katharina Heinke ${ }^{\mathrm{a}}$ \& Dan \\ Engström ${ }^{c}$
}

\author{
${ }^{a}$ Chalmers University of Technology, S-41296, Gothenburg, Sweden \\ ${ }^{b}$ Chalmers University of Technology S-412 96 Gothenburg ,Sweden \\ ${ }^{c}$ Swerea IVF, Swedish Research, SE-431 22 Mölndal, Sweden
}

\begin{abstract}
The increasing use of Virtual Design and Construction, VDC, is changing the way of working in the construction industry. With the introduction of VDC follows the creation of new roles and new ways of communicating within construction projects. The overall aim of the present paper is to map industry practitioners' view on VDC professionals' role. This includes mapping their perceptions on what characteristics a VDC professional should possess, what roles they play today and what role they should play in the future, and also to what extent they are perceived to contribute to project success. In order to shed light on these questions a questionnaire was sent to respondents working in varying degrees with VDC, in one of Sweden's largest construction companies. The results show that there is little agreement concerning the goals of VDC within the company. Furthermore, opinions also vary considerably with regards to what responsibilities a VDC professional ought to take within projects, and at the same time expectations of the characteristics of a VDC professional are high. Finally, the results show that there is demand for higher involvement of VDC professionals as compared to their current involvement.
\end{abstract}

(C) 2015 The Authors. Published by Elsevier B.V. This is an open access article under the CC BY-NC-ND license (http://creativecommons.org/licenses/by-nc-nd/4.0/).

Selection and/ peer-review under responsibility of Tampere University of Technology, Department of Civil Engineering

Keywords: BIM; construction company; professional roles; questionnaire; virtual design and construction (VDC).

*Corresponding author. Tel.: +46-31-772-1957; fax: +46-31-772-1957.

E-mail address: mathias.gustafsson@ chalmers.se 


\section{Introduction}

The entrance of virtual prototyping and the introduction of new multi-dimensional technologies, such as 3D planning and Building Information Modelling (BIM) are predicted to change the way of working within the architecture, engineering and construction (AEC) industry (Elmualim and Gilder, 2014; Akintoye et al., 2012; Bosch-Sijtsema, 2013). VDC, here used synonymously with BIM-management in a broader sense (Volk et al, 2014), includes these new virtual technologies but also novel management approaches for organizing, communicating and collaborating in construction projects (Kunz and Fischer, 2012). VDC and BIM is claimed to improve design quality, construction safety and management efficiency in form of reduced costs and time for construction projects (Xu et al., 2014; Bryde et al, 2013; Huang et al., 2007). It is also believed to improve productivity and project performance (Azhar, 2011). Facilitating the sharing of information and knowledge between different actors throughout the whole construction process, VDC are also believed to fundamentally change the way information are communicated and transferred during and between the different stages of a construction process (Bosch-Sijtsema, 2013; Russell et al., 2013).

To organize and handle the diversity of project data and the distributed information connected to a complex BIM model is not a small task, and requires management (Weygant, 2011). To handle this new way of information flow and support the changed way of working specialized staff and competence is needed as a new knowledge domain is created through the introduction of VDC and BIM (Elmualim and Gider, 2013; Akintoye et al., 2012). To meet this need of expertise knowledge and specialist skills within the AEC industry some researchers have suggested an introduction of a new profession (Mourgues et al., 2007; Russell et al. 2013). Others have suggested that instead of a new profession the new way of working should be in cooperated within existing roles (CURT 2010, in (Russell et al., 2013). Irrespectively, the introduction of these new technologies and work methods within established working environment has nurtured a development of new VDC related roles in the AEC industry (Jaradat et al., 2013). Bosch-Sijtsema (2013) for instance identifies two roles; one technical professional role and one facilitator role, where the facilitator would manage the information and communication flow within the project whereas the technical professional would handle the virtual model. Weygant (2011) take another approach and unites these roles and suggest an introduction of a specific knowledge manager as: "a hybrid of specifier, CAD manager and BIM content developer".

In order to act and influence, these professionals are dependent on how their role and practice are received and established within the organization as well as in the AEC industry as a whole. Thus, in order to utilize the possibilities of VDC it is crucial to not only educate specialists and experts within VDC but also all employees within the AEC process (Elmualim and Golder, 2013; Mourgues et al., 2007). To have basic skills regarding the use of VDC and BIM methods and tools are believed as unavoidable for professionals active in the AEC industry (Russell et al., 2013).

However, lack of clarity regarding roles and responsibility has been identified as some major barriers for the introduction and fully utilization of VDC and BIM (eg. Gu and London, 2010). To create clarity regarding roles and functions of VDC professionals present paper map practitioners' perceptions on what characteristics a VDC professional should possess, what roles they play today and what role they should play in the future, and also to what extent they are perceived to contribute to project success.

\section{Method}

The studied company is one of the leading construction and property developing companies in the Nordic region with approximately 20000 employees and a turnover of circa 60 billion SEK (year 2013). The company develops and builds residential and commercial properties, industrial facilities and public buildings, roads, civil engineering structures and other types of infrastructure divided into three business areas: Industrial, construction and civil engineering, and development.

To collect the quantitative data a questionnaire survey was sent out to employees in the company. The focus of 
the survey was to collect opinions from project managers, production managers and design managers due to their position within the organization considering whether or not VDC should be in cooperated to the project and to which degree. In the results we present the results from a subset of the questionnaire. Using a web based survey program, the survey was sent through email to 173 employees in the company. Due to the nature of the questions the employees that were of interest for the survey needed to have some kind of relation or connection to VDC-projects. For example, they are VDC professionals (VDC- specialists and/or coordinator), worked together with the VDC professionals or had worked in construction projects where VDC were used. After the first invitation was sent, engaging to participate in the survey, two additional reminding emails were sent before the survey was closed. In total 102 respondents answered the survey (59\% response rate). 84 questionnaires were fully completed, giving a response rate of $49 \%$. Among the respondents $1 / 3$ were assigned to work, fulltime or part time, in a VDC function in the company, either as coordinator or as specialist.

\section{Results}

In the following we present descriptive results in the form of percentages of response options to various questions posed in the questionnaire.

\subsection{Definitions and perceived benefits from VDC}

To get an understanding of the respondents' general attitude towards VDC they were asked to define VDC and answer on how they perceive corporate benefits from working with VDC.

Although the respondents have mixed opinions regarding the existence of a clear definition of what VDC entails they do agree on that VDC do not only mean use of 3D-models. Also the idea of VDC as a supporting function to the construction projects has large support among the respondents. The most spread answers concerned the claim that VDC permeates all business activities, where some respondents strongly agree while others disagree. Moreover, even if the respondents agree that there is a clear focus on VDC within the company they have various opinions regarding if there are clear goals for the use of VDC within the company or not. Thus, a rather fragmented view on VDC appears.

The results show that more than $60 \%$ believe that VDC increases the company's profitability, that it contributes to more efficient work processes and that it improves the projects' quality and end results (see Fig. 1)., Moreover, contrary to research claims, a more uncertain benefit from VDC is shortened construction time and some respondents also experience that VDC involves additional workload in the projects. Furthermore, the survey shows that the asked employees' perception is that VDC has a positive impact on information management; the communication within projects and the number of problems that need to be solved on site. 
VDC contributes to shorter construction time

VDC in the projects improves the end result

There are clears goals for the use of

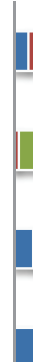

VDC entails more work in the projects

VDC increases the quality in projects

VDC contributes to more efficient work processes

There is a clear definition of what $\mathrm{VDC}$ is

VDC is a supporting function to construction projects

There is a clear focus on VDC

VDC permeates all business
activites

VDC increases profitability

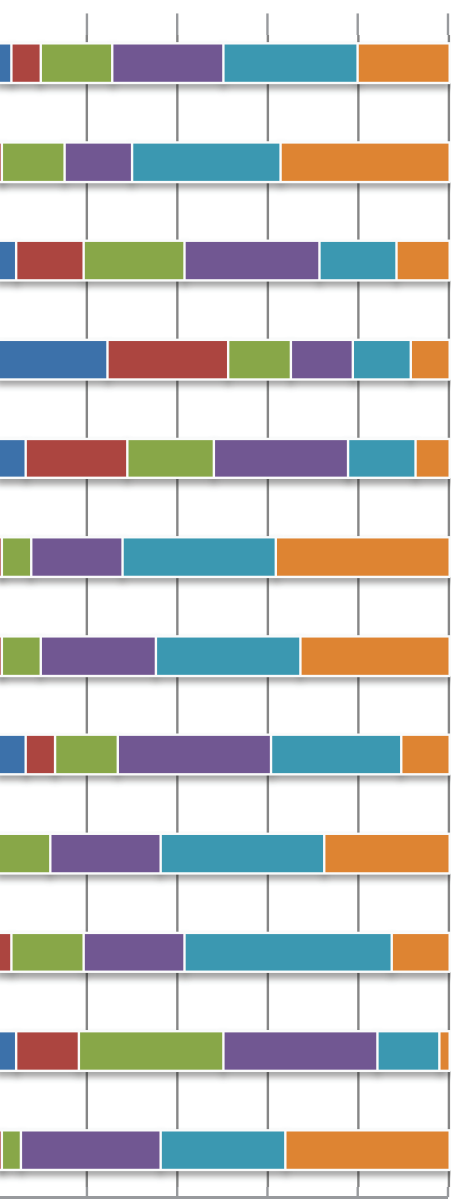

- Totally disagree

- Disagree to a large

extent

- Disagree

- Agree

- Agree to a large extent

- Totally agree

$\begin{array}{llllll}0 \% & 20 \% & 40 \% & 60 \% & 80 \% & 100 \%\end{array}$

Fig. 1. Response to the question "What is your perception regarding VDC within the company?".

\subsection{Characteristics and tasks of VDC professionals}

There are really high expectations of the characteristics of a VDC professional. They are especially expected to be structured, pedagogic, be a good collaborator, show dedication, be proactive and have good communicative skills. The two less important characteristics are diplomacy and leadership skills.

The knowledge and experiences that the VDC professionals should have according to the survey is 'technical knowledge concerning 3D-modelling', 'understanding of the construction process' and 'understanding of the involved professional groups' needs'. These and also experience from design and/or production are all ranked higher rated than a formal university education. Furthermore a master degree is lower ranked than a bachelor degree, which in turn is ranked lower than a general training within computer science/IT. This indicates that experience is favoured over education and that it is not necessary to have a higher education degree.

The result from the survey shows that there is not a unison view on whether the VDC- professional's tasks are clearly defined or not (see Fig. 2). There is a tendency of vagueness regarding what a VDC professional should do in a project. Only $2 \%$ answer that it is clearly defined to a very high extent. The result is spread but a majority disagree 
that it is clearly defined what a VDC professional should do. According to the answers from the survey, the tasks that the most of the respondents think a VDC professional should do is: 'Create and manage the coordination model', 'Manage VDC Requirement Document', 'Collocate VDC-experience from the project' and 'Clash detection'. Other high rated tasks are 'Quality control of the model', 'support collaboration through visualization of the models'. To 'facilitate communication', 'define metrics' and 'simulations of work preparation' are the lowest rated tasks according to the survey. The most disagreement among the respondents concerned whether or not the VDC professional should define and manage metrics and the quality assurance of delivery to customer. The same tasks are requested that a VDC professional should do when the groups are viewed independently, although the answers from the VDC group are more united than those in the other group, which show more variation.

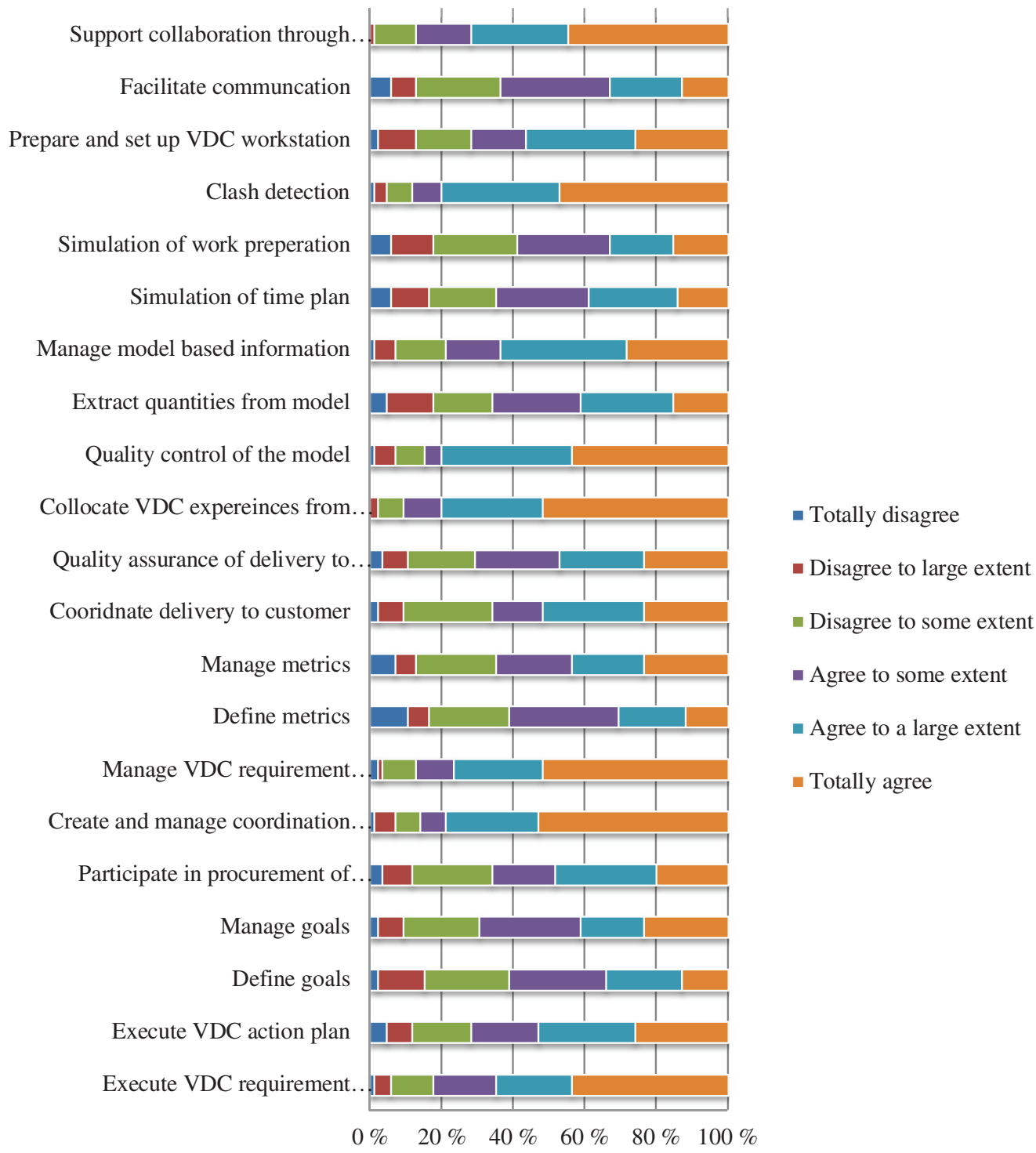

Fig. 2. Response to the question "To what extent do these task correspond to what you believe a VDC professional should do in a project?". 


\subsection{VDC professionals' involvement in and influence on project outcome}

Fig. 3 presents and compares responses on the two questions; "How involved is VDC professionals in the projects today?" and "How involved should VDC professionals be in the projects in the future?". The results show that compared to today, a higher involvement of the VDC professional in all phases, from sales to hand-over, is sought for (see figure 3). Most involvement today is not so surprisingly in the design and construction phases, although there still seem to be possibilities of improvements in term of presence also in these phases. Least involvement is in the sale phase, which is also the phase were the VDC professionals are perceived to be least involved also in the future. Seen to the results there seem to be a greater need for the VDC professionals to be more involved in the tendering and in the hand-over to client phases than today. Overall the two respondent groups, VDC professionals respectively managers, correspond to the total result of the survey regarding the involvement in various phases although VDC professionals show a tendency to wish for a higher extent of involvement in all phases

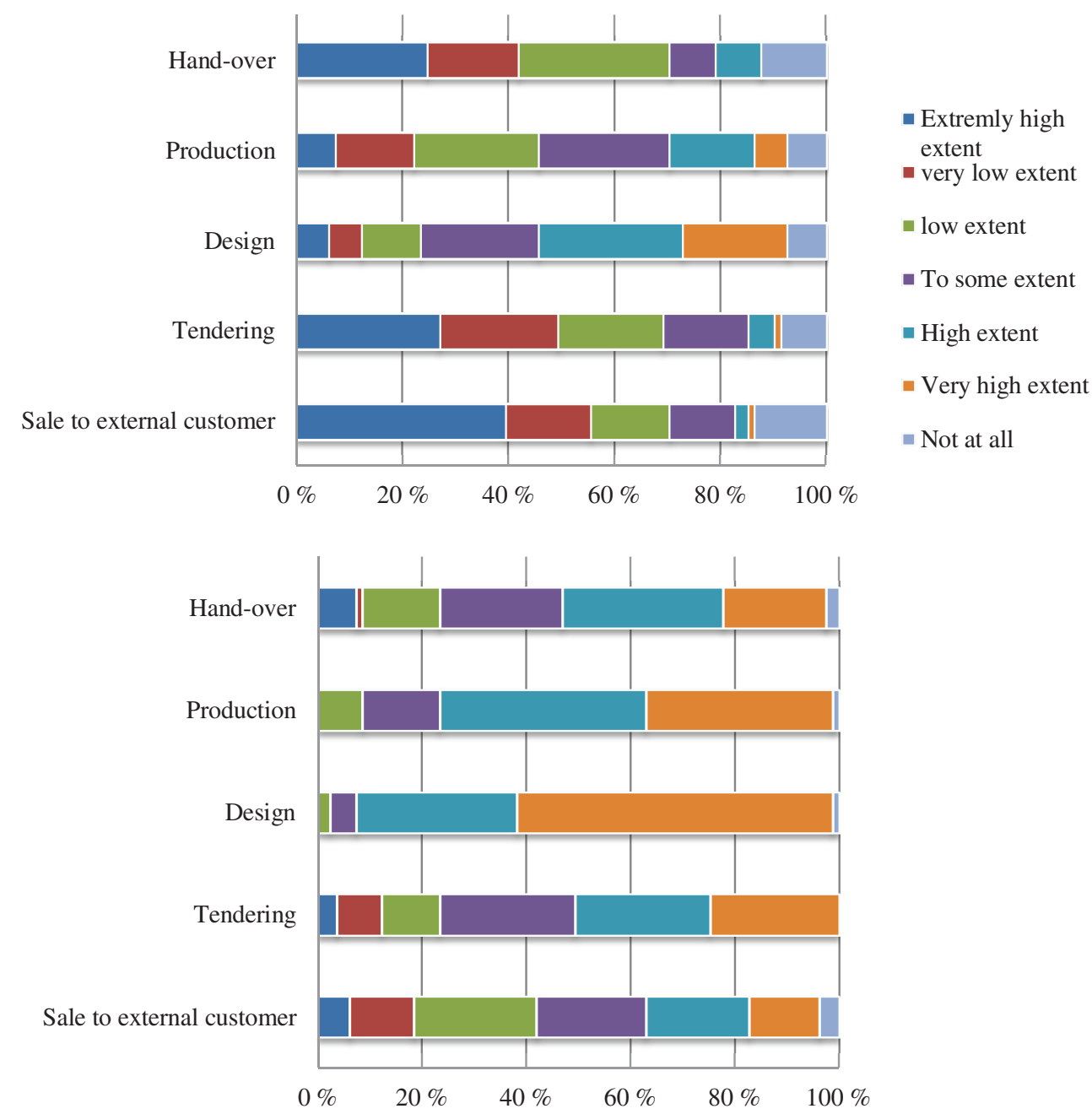

Fig. 3. Response to the question "How involved is VDC professionals in the projects today?".(top panel) and response to the question "How involved should the VDC professional be in the projects in the future?" (bottom panel). 
The majority of the respondents believe that the VDC professionals role is significant for the success of a project and only $18 \%$ think that the VDC professional has 'low significant' or 'very low significant' for the success of a project (see Fig. 4).

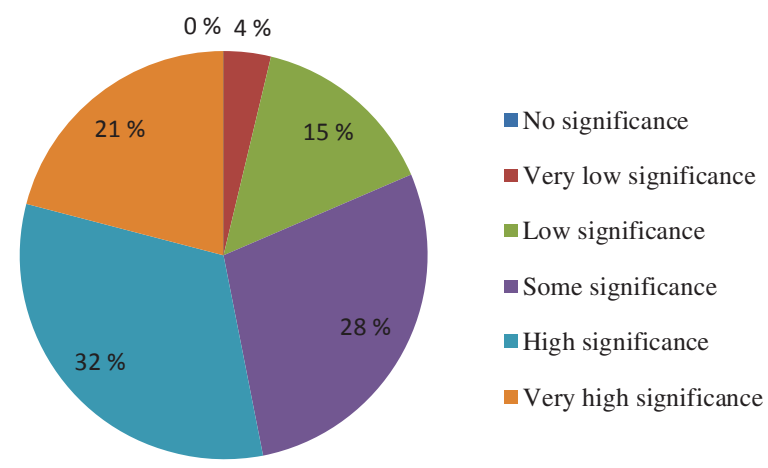

Fig. 4. Response to the question "What significance do you believe that the VDC professional role has for the success of a project?".

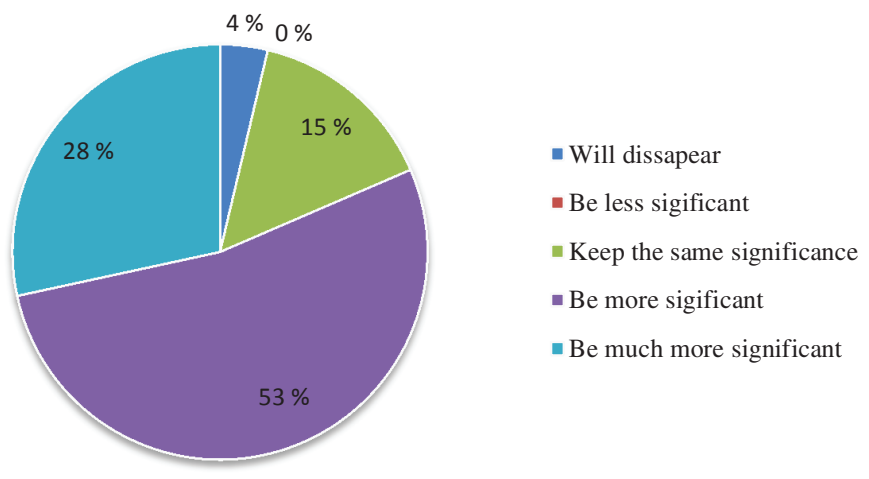

Fig. 5. Response to the question "How do you believe that the VDC professional's function will develop in the future?",

When looking at how respondents view the future the survey result shows that the majority of the respondents believe that the VDC professional role will be more significant in the future (see Fig. 5). From open comments on the question related to a future development of VDC roles and function keywords as 'an important spider in the global information net' and 'key person' are forwarded. An VDC professional are also hoped to have an 'overreaching responsibility' and 'someone with a good sense of the right level for the project but also with an urge to experiment some'.

Similar to the researchers' disagreement also the respondents display disagreement regarding if the VDC-role should be a separate profession or integrated into other more traditional professions. From the open comments there are voices that proclaim that the VDC profession will slowly grow and become a natural party in the AEC industry and soon be on an equal foot with other more established professions. In this lies having enough authority and finances to push the issues harder than is done today. Others believe the role is temporary, when the broad mass of practitioners has gained knowledge and feel comfortable enough working with these issues on their own, the role will disappear. 


\section{Concluding remarks}

The aim of the study was to describe and define the professional roles, which has emerged from the implementation of the new technology VDC. The overall impression from the analysis of the survey answers is that VDC as a new technology is seen as something positive and important for the studied company's future success. A large majority of respondents agree on that the role of the VDC professional will be of larger importance in the future. This stresses the need for continued development of this role both in industry and in engineering education. Another important finding is that there is mismatch between to what extent VCD professionals currently are involved in different phases of a project and to what extent they, from the perspective of the respondents, should be. This holds for all phases, including tendering, sale to external customer and handover and no just the more "technical phases" such as design and production. If this will lead to larger involvement, it implies that the scope of activities for the VDC professional will increase. Should the VDC professional be used as a knowledge carrier or should the VDC professional be a profession that fulfil the demand formulated by research? Hence be a new profession within projects that deals with information and data management along with the responsibility for the visualization model or be a knowledge sharing mechanism. The authors' point of view is to use the VDC professional as a knowledge carrier as well as a profession within project work. In terms of the practical implications of the current work, we see it more as a contribution to a wider discussion concerning the implementation of new tools and ways of working, and on how this is both perceived and adopted within the industry. There is a tendency of having to much a focus on the technical aspects when new technology is introduced on the expense of the more "softer aspects" such as how this new technology is perceived and how it both change roles as well as gives rise to new types of roles. Concerning the data used, we have to briefly discuss its ecological validity. The data collected comes from one company, albeit one of the largest contactors in Sweden, thus we cannot as of yet make any strong claims regarding the generality of the results in terms of how the industry in general view the VDC-profession and its uses. Therefore, we plan to, in a next step, to test the generality of our findings by investigating a larger and more representative sample of the industry.

\section{References}

Akintoye, A., Goulding, J. \& Zawdie, G. 2012. Construction Innovation and Process Improvement, Wiley.

Azhar, S. 2011. Building Information Modeling (BIM): Trends, Benefits, Risks and Challenges for the AEC Industry. Leadership and Management in Engineering, 241-252.

Bosch-Sijtsema, P. 2013. New ICT changes working routines in construction design projects. Nordic Academy of Management (NFF) Iceland, August 2013, 2013.

Bryde, D., Broquetas, M. \& Volm, J.M. 2013. The project benefits of Building Information Modelling (BIM). International Journal of Project management, 971-980.

Elmualim, A. \& Gilder, G. 2014. BIM: innovation in design management, influence and challenges of implementation. Architectural Engineering and design management, 3-4, 183-199.

Gu, N. \& London, K. 2010. Understanding and facilitating BIM adoption in the AEC industry. Automation in construction, 19, 988-999.

Huang, T., Kong, C., Guo, H. L., Baldwin, A. \& Li, H. 2007. A virtual prototyping system for simulating construction processes. Automation in Construction, 16, 576-585.

Jaradat, S., Whyte, J. \& Luck, R. 2013. Professionalism in digitally mediated project work. Building Research \& Information, 41, 51-59.

Kodama, M. 2006. Project-based Organization in the Knowledge-based Society: Innovation by Strategic Communities (Technology Management), Imperial College Press.

Kunz, J. \& Fischer, M. 2012. Virtual Design and Construction: Themes, Case Studies and Implmentation Suggestions. CIFE Working Paper no 97. Stanford University.

Mourgues, C., Fischer, M. \& Hudgens, D. 2013. Using 3D and 4D models to improve jobsite communication-virtual huddles case study. Proceedings of CIB 24th W78 Conference \& 14th EG-ICE Workshop \& 5th ITC@ EDU Workshop, Maribor (Slovenia), 2007. 91-97.

Russell, D., Cho, Y. K. \& Cylwik, E. 2013. Learning Opportunities and Career Implications of Experience with BIM/VDC. Practice Periodical on Structural Design and Construction, 19, 111-121.

Volk, R., Stengel, J. \& Schultmann, F. 2014. Building Information Modelling (BIM) for existing buildings - Literature review and future needs. Automation in Construction, 109-127.

Weygant, R. S. 2011. BIM Content Development: Standards, Strategies, and Best Practices, John Wiley \& Sons.

Xu, H., Feng, J. \& Li, S. 2014. Users-orientated evaluation of building information model in the Chinese construction industry. Automation in Construction, 39, 32-46. 